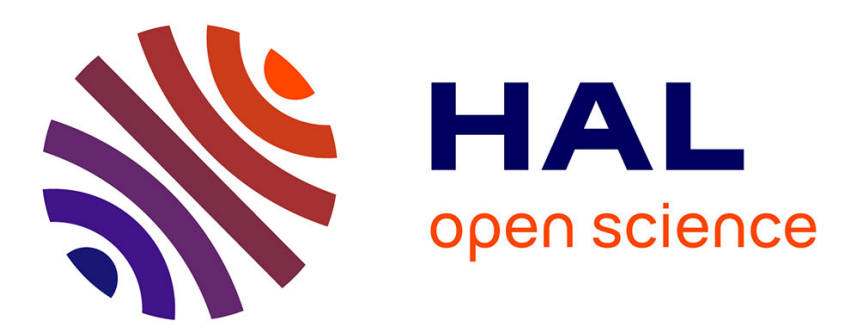

\title{
Randomized controlled trial of a 'nudge' strategy to modify endoscopic sedation practice
}

Gavin Harewood, Karl Clancy, Jean Engela, Mona Abdulrahim, Kieran Lohan, Claire O’Reilly

\section{- To cite this version:}

Gavin Harewood, Karl Clancy, Jean Engela, Mona Abdulrahim, Kieran Lohan, et al.. Randomized controlled trial of a 'nudge' strategy to modify endoscopic sedation practice. Alimentary Pharmacology and Therapeutics, 2011, 34 (2), pp.229. 10.1111/j.1365-2036.2011.04703.x . hal-00642379

\section{HAL Id: hal-00642379 \\ https://hal.science/hal-00642379}

Submitted on 18 Nov 2011

HAL is a multi-disciplinary open access archive for the deposit and dissemination of scientific research documents, whether they are published or not. The documents may come from teaching and research institutions in France or abroad, or from public or private research centers.
L'archive ouverte pluridisciplinaire HAL, est destinée au dépôt et à la diffusion de documents scientifiques de niveau recherche, publiés ou non, émanant des établissements d'enseignement et de recherche français ou étrangers, des laboratoires publics ou privés. 


\begin{tabular}{l}
\hline Alimentary Pharmacology \\
\hline \& Therapeutics \\
\hline
\end{tabular}

\section{Randomized controlled trial of a 'nudge' strategy to modify endoscopic sedation practice}

\begin{tabular}{|r|l|}
\hline Journal: & Alimentary Pharmacology \& Therapeutics \\
\hline Manuscript ID: & APT-0149-2011.R1 \\
\hline Wiley - Manuscript type: & Original Scientific Paper \\
\hline Author: & $28-$ Mar-2011 \\
\hline Complete List of Authors: & $\begin{array}{l}\text { Harewood, Gavin; Beaumont Hospital, Gastroenterology } \\
\text { Clancy, Karl; Royal College of Physicians Medical School } \\
\text { Engela, Jean; Royal College of Physicians Medical School } \\
\text { Abdulrahim, Mona; Royal College of Physicians Medical School } \\
\text { Lohan, Kieran; Royal College of Physicians Medical School } \\
\text { O'Reilly, Claire; Royal College of Physicians Medical School }\end{array}$ \\
\hline Keywords: & $\begin{array}{l}\text { Colonoscopy < Topics, Endoscopy < Topics, Guidelines < Topics, } \\
\text { Outcomes research < Topics, Sedation < Topics }\end{array}$ \\
\hline
\end{tabular}




\title{
Randomized, controlled trial of a 'nudge' strategy to modify endoscopic sedation practice
}

\author{
Gavin C. Harewood, MD, MBA, MSc, FASGE* \\ Karl Clancy** \\ Jean Engela ** \\ Mona Abdulrahim** \\ Kieran Lohan** \\ Claire O’Reilly** \\ *Department of Gastroenterology \& Hepatology, \\ Beaumont Hospital Dublin, \\ Ireland \\ **Royal College of Surgeons of Ireland Medical School, \\ Dublin, \\ Ireland \\ Corresponding Author Information: \\ Phone: (353)18092003 \\ Email: harewood.gavin@gmail.com
}




\begin{abstract}
:
Background: In behavioural economics, a nudge describes configuration of a choice to encourage a certain action without taking away freedom of choice. This study aimed to determine the impact of a nudge strategy - pre-filling either $3 \mathrm{~mL}$ or $5 \mathrm{~mL}$ syringes with midazolam - on endoscopic sedation practice.

Methods: Consecutive patients undergoing sedation for EGD or colonoscopy were enrolled. On alternate weeks, midazolam was prefilled in either $3 \mathrm{~mL}$ or $5 \mathrm{~mL}$ syringes. Pre-procedure sedation was administered by the endoscopist in order to achieve moderate conscious sedation, dosages were at the discretion of the endoscopist. Meperidine was not prefilled.

Results: Overall, 120 patients received sedation for EGD (59 [5 mL], 61 [3 mL]) and 86 patients were sedated for colonoscopy (38 [5 mL], 48 [3 mL]). For EGDs, average midazolam dose was significantly higher in the $5 \mathrm{~mL}$ group $(5.2 \mathrm{mg}$ ) vs $3 \mathrm{~mL}$ group (3.3 mg), p < 0.0001; for colonoscopies, average midazolam dose was also significantly higher in the $5 \mathrm{~mL}$ group $(5.1 \mathrm{mg})$ vs $3 \mathrm{~mL}$ group $(3.3 \mathrm{mg}), \mathrm{p}<0.0001$. There was no significant difference in mean meperidine dose ( $42.1 \mathrm{mg}$ vs $42.8 \mathrm{mg}, \mathrm{p}$ $=0.9$ ) administered to both colonoscopy groups. No adverse sedation related events occurred; no patient required reversal of sedation.

Conclusions: These findings demonstrate that nudge strategies may hold promise in modifying endoscopic sedation practice. Further research is required to explore the utility of nudges in impacting other aspects of endoscopic practice.
\end{abstract}


Introduction:

The term 'nudge' is used to describe configuration of a choice to encourage a certain course of action without taking away freedom of choice. It has been popularized in recent years following publication of the book "Nudge: Improving Decisions about Health, Wealth, and Happiness" by Richard Thaler and Cass Sunstein, two economists from the University of Chicago (1). The book uses principles of psychology and behavioural economics to explore the science of decision-making and the role of nudges that preserve freedom to make choices while encouraging people to make better ones. This branch of behavioural science is already widely used in shaping many aspects of public policy. Examples of nudges include automatic enrolment in 401(k) plans that require people to opt out if they don't want to save for retirement or meters that warn people about the amount of energy being used to encourage them to reduce energy use.

Despite its popularity in public policy decisions, to date there are few published studies in the medical literature evaluating the impact of nudge strategies on routine clinical care. This study was designed to evaluate the impact of a nudge strategy on endoscopic sedation practice. Provision of adequate sedation is a key component of endoscopy practice. Most endoscopic procedures are performed with the patient under moderate conscious sedation, a level of sedation at which the patient can still respond to verbal stimulation. Routinely, this is achieved through administration of a benzodiazepine and/or narcotic. Although both the American Society of Gastrointestinal Endoscopy (ASGE) (2) and the British Society of Gastroenterology (BSG) (3) have published guidelines regarding safe sedation practice, significant inter-endoscopist variation exists in the doses of sedatives administered (4). This study aimed to determine the impact of pre-filling either $3 \mathrm{~mL}$ or $5 \mathrm{~mL}$ syringes with midazolom - the nudge - on the behaviour of endoscopists when administering sedation. 


\section{Methods:}

This study was conducted in Beaumont Hospital, Dublin, Ireland. This is a tertiary care referral hospital affiliated with the Royal College of Surgeons of Ireland medical School. Consecutive outpatients scheduled for EGD or colonoscopy who opted to receive conscious sedation were enrolled over the course of the eight week study period, June and July 2010. Routinely, in this endoscopy unit, approximately 80-90\% of patients undergoing EGD elect to receive sedation while almost all patients undergoing colonoscopy opt for sedation. Patients undergoing flexible sigmoidoscopy were not enrolled as this procedure is generally performed without sedation in this hospital. To achieve moderate conscious sedation, patients undergoing EGD routinely receive midazolam; patients undergoing colonoscopy routinely receive midazolam and meperidine in this endoscopy unit. Procedures were performed by six endoscopists each with experience of independently performing at least 3,000 EGDs and at least 3,000 colonoscopy procedures.

Prior to commencement of this study, both $3 \mathrm{~mL}$ and $5 \mathrm{~mL}$ syringes were routinely used for midazolam in this endoscopy unit. Endoscopists transferred midazolam from the vial to the syringe immediately prior to administration to the patient on an asrequired basis. None of the six endoscopists either consistently used one volume syringe nor had a strong preference for one volume syringe over another. For the duration of the study, midazolam was prefilled in either $3 \mathrm{~mL}$ (containing $6 \mathrm{mg}$ midazolam) or $5 \mathrm{~mL}$ (containing $10 \mathrm{mg}$ midazolam) syringes on alternate weeks. Multiple syringes were prefilled with midazolam by the endoscopist prior to commencement of the procedure list - a sufficient number of syringes for all the patients scheduled for that list. Therefore, although patients were blinded to the size of syringe used, endoscopists were aware of syringe size. Meperidine syringes were not prefilled. Meperidine was transferred from the vial to a standard $2 \mathrm{~mL}$ syringe on an as-required basis immediately prior to administering to the patient. All syringes were clearly labelled with the contained sedative agent.

Endoscopists aimed to achieve moderate conscious sedation during procedures, a level of sedation during which verbal responsiveness was maintained with the patient. There were an ample number of pre-filled syringes available for each procedure. 
All six endoscopists performed approximately equal proportions of their procedures on the $3 \mathrm{~mL}$ and $5 \mathrm{~mL}$ syringe weeks and patients were randomly assigned among endoscopists. This reduced the confounding effect of sedation practices of individual endoscopists (i.e. whether they were 'heavy sedators' or 'light sedators') on the findings. Patient demographic information, sedation dosages, procedure duration, adverse sedation related events (e.g., hypoxia, hypotension) and the need to administer a sedation reversal agent (e.g., flumazenil) were recorded for each procedure. Ethical approval for the study was obtained from the Institutional Review Board.

\section{Statistical analysis:}

To detect a difference of $0.2 \mathrm{mg}$ in sedative dose between patient groups, which we considered to be clinically significant, a sample size of 32 patients per group was required, given with a two-sided $5 \%$ significance level and a power of $80 \%$. The primary endpoint of this study was the dose of sedative required to achieve moderate conscious sedation. Comparison of categorical variables, which were all normally distributed, was performed by chi-squared test for parametric data while comparison of continuous variables was performed by Student $t$ test. A p value of $<0.05$ was considered statistically significant. 


\section{Results:}

Overall, 120 patients received sedation for EGD procedures (Figure 1); 59 patients in the $5 \mathrm{~mL}$ group and 61 patients in the $3 \mathrm{~mL}$ group; all patients received midazolam. Eighty-six patients were sedated for colonoscopy; 38 patients in the $5 \mathrm{~mL}$ group and 48 patients in the $3 \mathrm{~mL}$ group; all these patients received a combination of midazolam and meperidine. There were no statistically significant differences in patient demographic features and procedure durations of both patient groups, as illustrated in table 1 .

EGD patient groups:

For EGDs, average midazolam dose was significantly higher in the $5 \mathrm{~mL}$ group $(5.2$ $\mathrm{mg}$ ) vs $3 \mathrm{~mL}$ group (3.3 mg), p $<0.0001$, as illustrated in Figure 2. There were no adverse sedation related events in either patient group and no patients required reversal of sedation.

\section{Colonoscopy patient groups:}

The average midazolam dose administered to patients undergoing colonoscopy was significantly higher in the $5 \mathrm{~mL}$ group $(5.1 \mathrm{mg})$ vs $3 \mathrm{~mL}$ group $(3.3 \mathrm{mg}), \mathrm{p}<0.0001$, as shown in Figure 2. There was no significant difference in mean meperidine dose (42.1 mg vs $42.8 \mathrm{mg}, \mathrm{p}=0.9$ ) administered to both groups, as illustrated in Figure 3. No adverse sedation related events occurred in either patient group and no patient required reversal of sedation. 
Discussion:

The findings of this study demonstrate that nudge strategies may hold promise in modifying endoscopic sedation practice and, indeed, may even be of benefit when applied more broadly to other aspects of endoscopists' behaviour. This is the first randomized controlled trial to date to assess the impact of nudges on endoscopic sedation practice. Both the ASGE (2) and BSG (3) guidelines on endoscopic sedation practice advocate a practice of achieving moderate conscious sedation through administration of the minimum sedative dose required to provide adequate patient comfort. Our findings illustrate the power of a subtle modification in routine practice (altering syringe size) in facilitating conscious sedation with lower, and one would suspect, safer sedation doses.

The science of choice architecture - the manner in which decisions are influenced by how choices are presented - was widely popularized in the book "Nudge: Improving Decisions about Health, Wealth, and Happiness" (1). This publication contains many examples of nudges which are increasingly being integrated into everyday life. A simple but effective example is the placement of healthy foods in a school cafeteria at eye level, while making less healthy junk food harder to reach. In this scenario, school children are not prevented from eating what they want; however the food choices are arranged so that junk food consumption decreases and healthier foods are more likely to be consumed. In the context of health care policy, nudge strategies carry enormous potential. To increase organ donation rates, some policy makers argue that for drivers to renew their driver license, they should be required to state their organ donor status. An alternative more radical approach that has been proposed would even mandate individuals to opt out of being an organ donor rather than opt in. In our study, although endoscopists were aware of the differences in syringe size and were aware that sedation doses were being recorded, they were unaware of the study hypothesis (i.e. that smaller syringes would 'nudge' them towards administering lower doses of sedation). Interestingly, endoscopists did comment during the study that they noticed they were inclined to give smaller sedation doses with the smaller pre-filled syringes, i.e. they were becoming aware of the 'nudge' effect. 
In the medical literature to date, perhaps the most common form of nudge to be studied is feedback and its impact in altering physicians' behaviour. In the gastroenterology literature, several studies have explored the role of feedback in enhancing colonoscopy performance. Overall, results have been mixed. A Mayo Clinic study assessed the impact of systematic feedback provided by e-mail on colonoscopy performance and found this to be associated with enhanced cecal intubation rates and shortened insertion times (5). Shaukat et al evaluated the impact of educational and quality improvement interventions on adenoma detection at colonoscopy in a community-based practice (6). These systematic interventions included individual feedback to endoscopists on their adenoma detection rates, personal discussions between practice leaders and poorly performing endoscopists and even financial penalties for excessively rapid withdrawal time. In contrast to the Mayo Clinic study, the results were disappointing. Despite the broad ranging nature of these nudges, the authors did not demonstrate any improvement in adenoma detection. Singh et al implemented a quality improvement initiative in a tertiary care Veteran Affairs facility to improve follow-up of FOBT positive results with good results (7). Quality improvement activities included education of Primary Care Providers regarding colorectal cancer screening guidelines and feedback on the timeliness of their referral of patients with positive FOBT for colonoscopy. Feedback took the form of both a computerized alert system and mail notification. The proportion of patients who received a timely colonoscopy referral and performance increased significantly post-feedback. The variable success of these nudge strategies illustrates the need for care when applying this approach. For maximum effect, a nudge should be tailored specifically to the target group. If the nudge takes the form of feedback, it needs to be compelling enough to alter behaviour. Similarly, financial incentives or penalties need to be customized to the target audience; only by characterizing the target group and understanding their priorities, their beliefs on tradeoffs and their values can targeted nudges be effectively implemented.

Sedation practice was considered a suitable area to apply a nudge strategy in this study as sedation dosages in endoscopy vary widely $(8,9)$. Although the ASGE has published guidelines on safe endoscopic sedation practice, no maximum doses of sedatives have been specified, rather dosages are left to the endoscopist's discretion (2). In contrast, the BSG does recommend that the average dose of midazolam not 
exceed $5 \mathrm{mg}$ for patients undergoing either EGD or colonoscopy (3). Interestingly, patients assigned to the $5 \mathrm{~mL}$ syringe group for both EGD and colonoscopy in our study received average midazolam doses in excess of this recommendation. An audit of endoscopy practice in the United Kingdom indeed demonstrated that $25 \%$ of patients routinely receive in excess of $5 \mathrm{mg}$ of midazolam for their endoscopic procedure (4). Despite these 'excessive' sedation doses, GI endoscopy remains a safe procedure. A review of over 14,000 EGD procedures has demonstrated a rate of cardiopulmonary incidents of $0.2 \%$ (10) while another review of over 21,000 procedures showed a similarly low rate of $0.5 \%$ for cardiovascular complications, ranging from transient hypoxemia to severe cardiorespiratory compromise (11). Reassuringly, in our study, there were no adverse sedation related complications although considering their infrequent occurrence, our study was underpowered to detect this endpoint. Nonetheless, it is desirable to achieve conscious sedation with as low a sedative dose as possible while providing adequate patient comfort. Our study findings indicate that routine use of a $3 \mathrm{~mL}$ rather than a $5 \mathrm{~mL}$ midazolam syringe facilitates conscious sedation with lower sedative doses. Although the initial bolus dose of sedation administered was not recorded in our study, all participating endoscopists reported that they routinely administered 2 to $3 \mathrm{mg}$ of midazolam as a bolus dose pre-procedure and that this practice was not impacted by the syringe size. They generally waited several minutes for this to take effect before determining if supplementary dosing, generally administered in 1 to $2 \mathrm{mg}$ increments, was required to achieve adequate sedation. It appears that the intra-group differences in midazolam doses arose from the differing supplementary doses given after the initial bolus.

Several limitations of this study are noteworthy. First, there was no measurement of patient satisfaction to assess adequacy of sedation from the patient's perspective or physician satisfaction with the ease of sedation administration. All endoscopists did sedate patients to adequate, safe levels and supplementary sedation was administered during procedures if any patient appeared to be in discomfort. This was entirely at the endoscopist's discretion and there was no limit to the quantity of sedation that could be administered in either patient group; for example, one patient required 20mg of midazolam. Similarly, as endoscopists had an ample number of pre-filled syringes of midazolam available in both patient groups, this should have limited any possible endoscopist dissatisfaction. However, relying on the endoscopist's estimation of 
patient comfort is not ideal and incorporation of a validated instrument for measuring patient comfort levels would have been preferable. Second, there are several factors which influence the level of sedative required to achieve adequate patient comfort. Patient weight, procedure duration, routine use of anxiolytic medication by the patient are all factors to be considered. Although procedure duration was recorded (and was not significantly different between both patient groups), other variables such as patient weight and regular benzodiazepine usage were not recorded. However, with the randomized design of the study, it would be expected that these variables would be evenly distributed among both patient groups. Third, although there are no statistically significant differences in the baseline demographics among the two groups (Table 1), the differences in both age and gender distribution may carry clinical significance. The $5 \mathrm{ml}$ syringe group was slightly younger (for both EGD and colonoscopy) and the $5 \mathrm{ml}$ colonoscopy group did have a higher proportion of female patients. Recognizing that older patients generally receive less sedation for safety reasons and that female patients tend to require higher doses of sedation, this may be contributing to the differences in sedation we observed among patient groups. Fourth, as mentioned above, our patient numbers did not gear us with sufficient power to demonstrate meaningful differences in sedation-related adverse outcomes between patient groups. However, as a proof-of-concept study, our results do succeed in demonstrating the utility of a nudge in lowering the sedation doses required to achieve moderate conscious sedation. The underlying assumption is that in larger patient cohorts this reduced sedation dose would translate into fewer sedation related adverse events and overall enhanced patient safety. Larger scale prospective studies would be required to answer this question.

In conclusion, this study provides interesting insight into the utility of nudge strategies in modifying endoscopic sedation practice. More specifically, our findings support the routine use of a $3 \mathrm{~mL}$ syringe rather than a $5 \mathrm{~mL}$ syringe for midazolam as this appears to be associated with administration of lower sedative doses to achieve conscious sedation which would enhance patient safety. Further studies will be helpful to explore the broader application of nudges in impacting other aspects of endoscopic practice. 
Table 1: Baseline features of patients in EGD and Colonoscopy patient groups, randomized to $3 \mathrm{~mL}$ and $5 \mathrm{~mL}$ midazolam syringes

\begin{tabular}{|c|c|c|c|c|c|c|}
\hline & EGD & & & Colonoscopy & & \\
\hline & $3 \mathrm{~mL}$ & $5 \mathrm{~mL}$ & $\begin{array}{l}\mathbf{p} \\
\text { value }\end{array}$ & $3 \mathrm{~mL}$ & $5 \mathrm{~mL}$ & $\begin{array}{l}p \\
\text { value }\end{array}$ \\
\hline No. pts & 61 & 59 & & 48 & 38 & \\
\hline $\begin{array}{l}\text { Mean age } \\
\text { (yrs) }\end{array}$ & 60.5 & 54.5 & 0.05 & 62.4 & 55.5 & 0.06 \\
\hline $\begin{array}{l}\text { Gender } \\
\text { (male/female) }\end{array}$ & $26 / 35$ & $24 / 35$ & 0.9 & $26 / 22$ & $13 / 25$ & 0.08 \\
\hline $\begin{array}{l}\text { Mean } \\
\text { procedure } \\
\text { duration } \\
(\text { mins) }\end{array}$ & 4.5 & 4.4 & 0.9 & 18.5 & 19.6 & 0.8 \\
\hline
\end{tabular}




\section{Figure Legends:}

Figure 1: Flow diagram of EGD and colonoscopy patient groups assigned to $3 \mathrm{~mL}$ and $5 \mathrm{~mL}$ syringes.

Figure 2: Mean dose of midazolam (mg) administered to patients undergoing EGD and colonoscopy in groups assigned to $3 \mathrm{~mL}$ and $5 \mathrm{~mL}$ syringes.

Figure 3: Mean dose of meperidine (mg) administered to patients undergoing colonoscopy in $3 \mathrm{~mL}$ and $5 \mathrm{~mL}$ patient groups. 


\section{References:}

1. Nudge: Improving Decisions about Health, Wealth, and Happiness. Yale University Press, 2008.

2. Waring JP, Baron TH, Hirota WK, et al. Guidelines for conscious sedation and monitoring during gastrointestinal endoscopy. Gastrointest Endosc 2003;58(3):317-22.

3. Teague R. Safety and sedation during endoscopic procedures. Endoscopy Sedation Committee, British Society of Gastroenterology, www.bsg.org

4. Bowles CJ, Leicester R, Romaya C, et al. A prospective study of colonoscopy practice in the UK today: are we adequately prepared for national colorectal cancer screening tomorrow? Gut 2004;53(2):277-83.

5. Harewood GC, Petersen BT, Ott BJ. Prospective assessment of the impact of feedback on colonoscopy performance. Aliment Pharmacol Ther 2006;24:31318.

6. Shaukat A, Oancea C, Bond JH, Church TR, Allen JI. Variation in detection of adeonomas and polyups by colonoscopy and change over time with a performance improvement program. Clin Gastro Hepatol 2009;7:1335-40.

7. Singh $\mathrm{H}$, Kadiyala $\mathrm{H}$, Bhagwath $\mathrm{G}$, et al. Using a multifaceted approach to improve the follow-up of positive fecal occult blood test results. Am J Gastro 2009;104(4):942-52.

8. Rex DK, Khalfan HK. Sedation and the technical performance of colonoscopy. Gastrointest Clin North Am 2005;15:661-72.

9. Cohen LB, Wecsler JS, Gaetano JN, et al. Endoscopic sedation in the United States: results form a nationwide survey. Am J Gastroenterol 2006;101:96774.

10. Quine MA, Bell GD, McCloy RF, Matthews HR. Prospective audit of upper gastrointestinal endoscopy in two regions in England: safety, staffing, and sedation methods. Gut 1995;36:462-67.

11. Arrowsmith JB, Gerstman BB, Fleischer DE, Benjamin SB. Results from the ASGE/US Food and Drug Administration collaborative study on complication rates and drug use during gastrointestinal endoscopy. Gastrointest Endosc 1991;37:421-27. 


\section{CONSORT 2010 checklist of information to include when reporting a randomised trial*}

\begin{tabular}{|c|c|c|c|}
\hline Section/Topic & $\begin{array}{l}\text { Item } \\
\text { No }\end{array}$ & Checklist item & $\begin{array}{l}\text { Reported } \\
\text { on page No }\end{array}$ \\
\hline \multicolumn{4}{|l|}{ Title and abstract } \\
\hline & $1 \mathrm{a}$ & Identification as a randomised trial in the title & 1 \\
\hline & $1 b$ & Structured summary of trial design, methods, results, and conclusions (for specific guidance see CONSORT for abstracts) & 2 \\
\hline \multicolumn{4}{|l|}{ Introduction } \\
\hline \multirow{2}{*}{$\begin{array}{l}\text { Background and } \\
\text { objectives }\end{array}$} & $2 a$ & Scientific background and explanation of rationale & 3 \\
\hline & $2 b$ & Specific objectives or hypotheses & 3 \\
\hline \multicolumn{4}{|l|}{ Methods } \\
\hline \multirow[t]{2}{*}{ Trial design } & $3 a$ & Description of trial design (such as parallel, factorial) including allocation ratio & 4 \\
\hline & $3 b$ & Important changes to methods after trial commencement (such as eligibility criteria), with reasons & 4 \\
\hline \multirow[t]{2}{*}{ Participants } & $4 a$ & Eligibility criteria for participants & 4 \\
\hline & $4 \mathrm{~b}$ & Settings and locations where the data were collected & 4 \\
\hline Interventions & 5 & $\begin{array}{l}\text { The interventions for each group with sufficient details to allow replication, including how and when they were } \\
\text { actually administered }\end{array}$ & 4 \\
\hline \multirow[t]{2}{*}{ Outcomes } & $6 a$ & $\begin{array}{l}\text { Completely defined pre-specified primary and secondary outcome measures, including how and when they } \\
\text { were assessed }\end{array}$ & 5 \\
\hline & $6 b$ & Any changes to trial outcomes after the trial commenced, with reasons & 4 \\
\hline \multirow[t]{2}{*}{ Sample size } & $7 a$ & How sample size was determined & 5 \\
\hline & $7 \mathrm{~b}$ & When applicable, explanation of any interim analyses and stopping guidelines & 5 \\
\hline \multicolumn{4}{|l|}{ Randomisation: } \\
\hline \multirow{2}{*}{$\begin{array}{l}\text { Sequence } \\
\text { generation }\end{array}$} & $8 a$ & Method used to generate the random allocation sequence & 4 \\
\hline & $8 b$ & Type of randomisation; details of any restriction (such as blocking and block size) & 4 \\
\hline $\begin{array}{l}\text { Allocation } \\
\text { concealment } \\
\text { mechanism }\end{array}$ & 9 & $\begin{array}{l}\text { Mechanism used to implement the random allocation sequence (such as sequentially numbered containers), } \\
\text { describing any steps taken to conceal the sequence until interventions were assigned }\end{array}$ & 4 \\
\hline Implementation & 10 & $\begin{array}{l}\text { Who generated the random allocation sequence, who enrolled participants, and who assigned participants to } \\
\text { interventions }\end{array}$ & 4 \\
\hline Blinding & $11 \mathrm{a}$ & If done, who was blinded after assignment to interventions (for example, participants, care providers, those & 4 \\
\hline
\end{tabular}


assessing outcomes) and how

$11 \mathrm{~b}$ If relevant, description of the similarity of interventions

Statistical methods

$12 \mathrm{a}$

$12 b$

Statistical methods used to compare groups for primary and secondary outcomes

Methods for additional analyses, such as subgroup analyses and adjusted analyses

\section{Results}

Participant flow (a diagram is strongly recommended)

Recruitment

Baseline data

Numbers analysed

Outcomes and

estimation

Ancillary analyses

Harms

\section{Discussion}

Limitations

Generalisability

Interpretation

\section{Other information}

Registration

Protocol

Funding 13a For each group, the numbers of participants who were randomly assigned, received intended treatment, and were analysed for the primary outcome

13b For each group, losses and exclusions after randomisation, together with reasons

14a Dates defining the periods of recruitment and follow-up

14b Why the trial ended or was stopped

15 A table showing baseline demographic and clinical characteristics for each group

16 For each group, number of participants (denominator) included in each analysis and whether the analysis was by original assigned groups

17a For each primary and secondary outcome, results for each group, and the estimated effect size and its precision (such as 95\% confidence interval)

17b For binary outcomes, presentation of both absolute and relative effect sizes is recommended

18 Results of any other analyses performed, including subgroup analyses and adjusted analyses, distinguishing pre-specified from exploratory

19 All important harms or unintended effects in each group (for specific guidance see CONSORT for harms)

20 Trial limitations, addressing sources of potential bias, imprecision, and, if relevant, multiplicity of analyses

21 Generalisability (external validity, applicability) of the trial findings

22 Interpretation consistent with results, balancing benefits and harms, and considering other relevant evidence

\begin{tabular}{l}
9 \\
\hline 9 \\
\hline 7
\end{tabular}

23 Registration number and name of trial registry

24 Where the full trial protocol can be accessed, if available

25 Sources of funding and other support (such as supply of drugs), role of funders

\begin{tabular}{l}
\hline 4 \\
\hline 5 \\
\hline 5 \\
\hline
\end{tabular}

6

6

4

4

$\frac{11}{6}$

\section{6}

$$
6
$$$$
6
$$

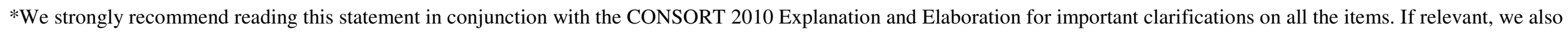

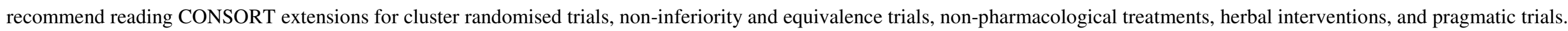
Additional extensions are forthcoming: for those and for up to date references relevant to this checklist, see www.consort-statement.org. 


\section{Figure 1: Flow diagram of patient groups}

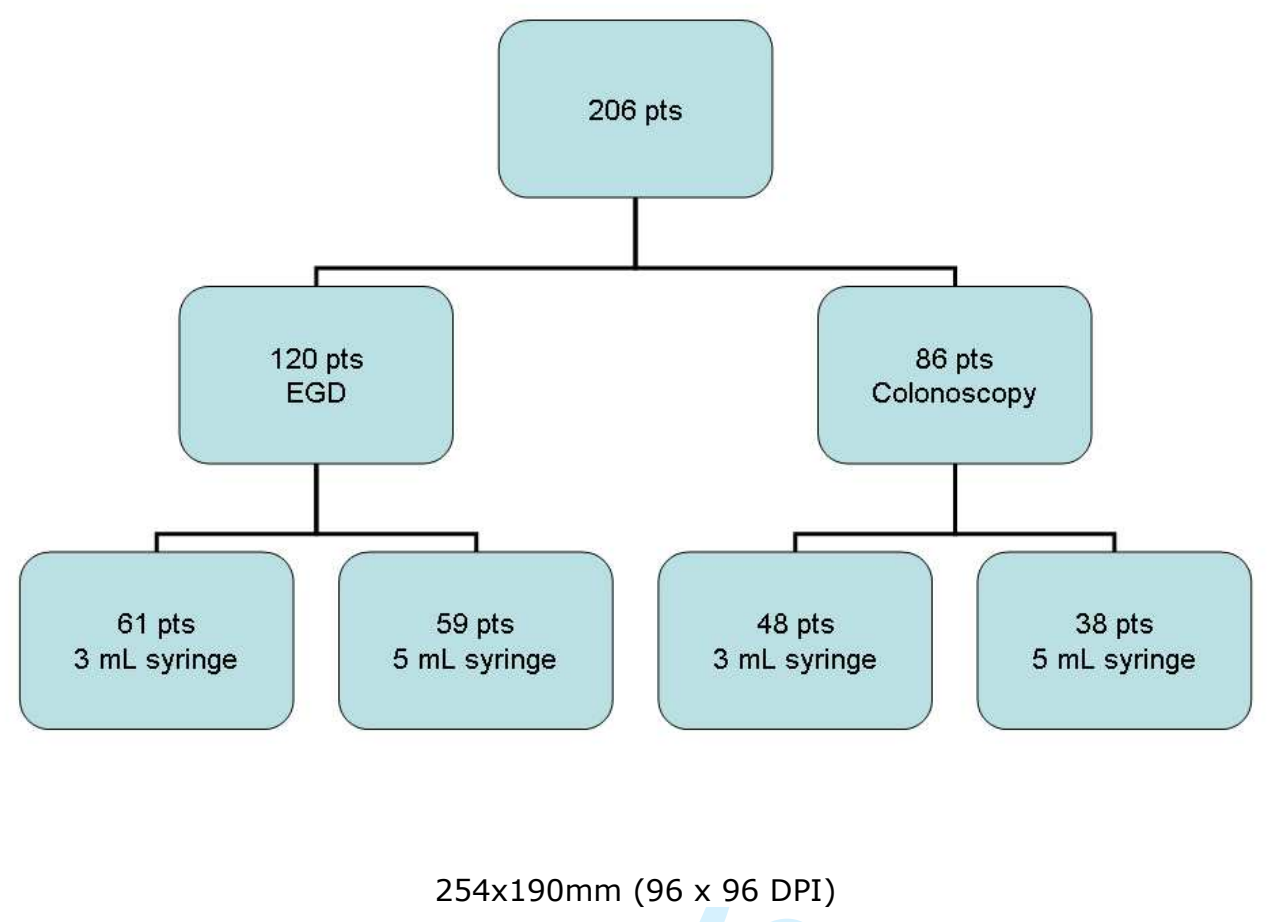




\section{Figure 2: Midazolam (mg) administered to patient groups}

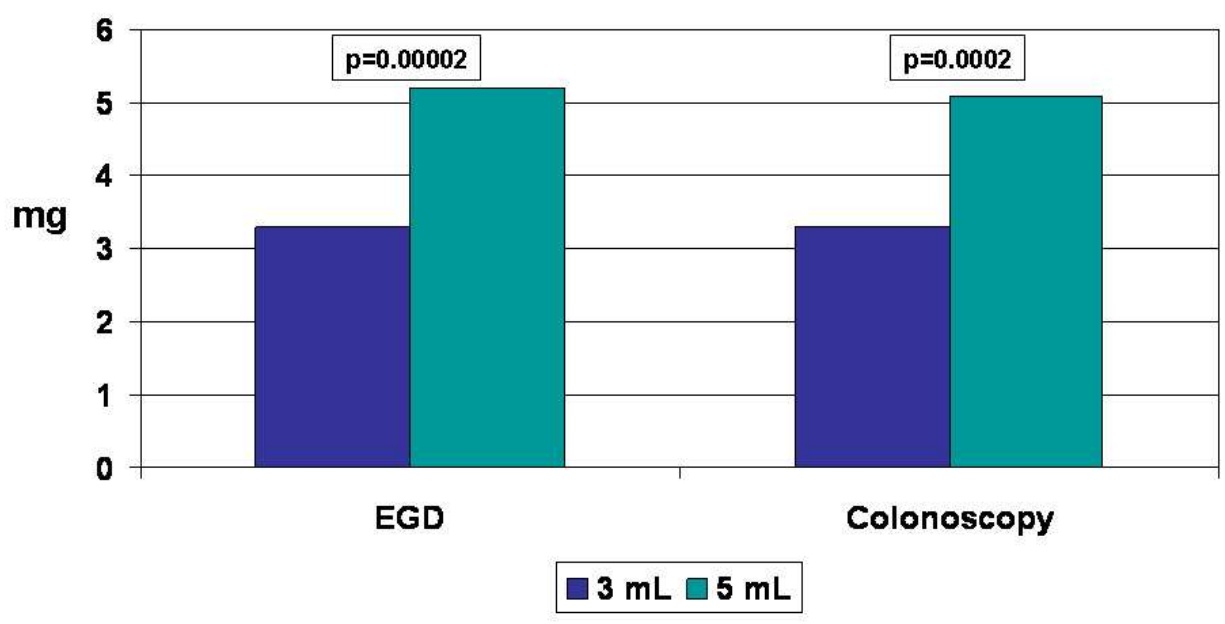

$254 \times 190 \mathrm{~mm}(96 \times 96$ DPI $)$ 


\section{Figure 3: Meperidine (mg) administered to patient groups}

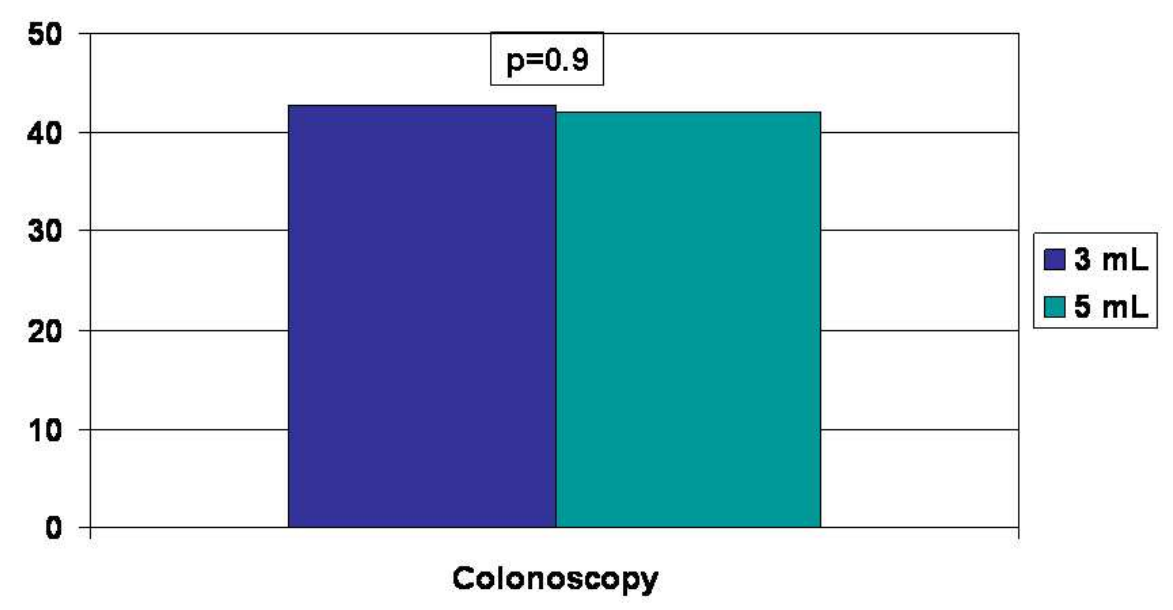

254x190mm (96 x 96 DPI) 